\title{
Assessment of anti-inflammatory effects of Japanese Kampo medicine and functional foods
}

\section{Mikio Nishizawa ${ }^{1}$, Tadayoshi Okumura ${ }^{2,3}$, and Yukinobu Ikeya ${ }^{4}$}

${ }^{1}$ Department of Biomedical Sciences, College of Life Sciences, Ritsumeikan University, Kusatsu, Shiga, 525-8577, Japan; ${ }^{2}$ Research Organization of Science and Technology, Ritsumeikan University, Kusatsu, Shiga, 525-8577, Japan; ${ }^{3}$ Department of Surgery, Kansai Medical University, Hirakata, Osaka, 573-1010, Japan; ${ }^{4}$ Department of Pharmacy Educational Assist Center, Daiich University of Pharmacy, Minami-ku, Fukuoka, 815-8511, Japan

Corresponding author: Mikio Nishizawa, M.D., Ph.D., Department of Biomedical Sciences, College of Life Sciences, Ritsumeikan University, 1-1-1 Nojihigashi, Kusatsu, Shiga, 5258577, Japan.

Submission Date: October $3^{\text {rd }}$, 2018, Acceptance Date: February $25^{\text {th }}$, 2019, Publication Date: February $28^{\text {th }}, 2019$

Citation: Nishizawa M., Okumura T., Ikeya Y. Comparison of anti-inflammatory effects of Japanese Kampo medicine and functional foods. Functional Foods in Health and Disease 2019; 9(2): 79-91. DOI: https://doi.org/10.31989/ffhd.v9i2.566

\begin{abstract}
Traditional Japanese drugs called Kampo medicine are widely used in Japan. Each Kampo medicine consists of several crude drugs, most of which are derived from medicinal plants. Clinical administration has empirically evaluated the effects of Kampo medicine. In contrast, functional foods are prepared from foods and edible plants (e.g., herbs, vegetables, and fruits). Due to the relatively low content of pharmacologically active constituents in functional foods, their effectiveness has not been well evaluated and thus should be better investigated. Kampo medicine and functional foods have beneficial effects for humans, and many of them exhibit anti-inflammatory effects. Here, we discuss the principles and methods to assess the antiinflammatory effects of functional foods and Kampo medicine.

To investigate pharmacological effects of functional foods and Kampo medicines, their constituents should be isolated to identify their chemical structures. Cell-based studies are commonly performed to evaluate anti-inflammatory effects of the constituents in Kampo
\end{abstract}


medicine and functional foods. Primary cultured rat hepatocytes are used and produce proinflammatory mediators, including nitric oxide. When an extract from a Kampo medicine, functional food, or a respective constituent is added to the medium, pro-inflammatory mediator production decreases, and the anti-inflammatory activity is estimated. Animal experiments have been performed using disease models, such as the endotoxemia model for animals, to which bacterial endotoxin is administered. Administering an effective functional food or Kampo medicine improves the survival of the model animals. The action of the antiinflammatory effects of functional foods and Kampo medicines can be investigated by the above-mentioned methods. The studies using cells and animals will provide a basis for the safe and effective use of functional foods and Kampo medicine in humans to treat diseases or improve health conditions.

Keywords: herbal drug, Kampo medicine, nitric oxide, inflammation, hepatocytes.

\section{COMPARISON OF KAMPO MEDICINE AND FUNCTIONAL FOODS}

Traditional Japanese medicine called Kampo medicine is widely used in Japan. Kampo medicine has the roots in ancient Chinese medicine, which was directly incorporated from China in the 7th century by diplomatic delegations, such as Kenzuishi and Kentoshi. In the 18th century (late Edo period), Chinese medicine was uniquely modified and adopted to Japanese people (i.e., Japanized), and Japanese Kampo medicine was developed. Although there was a decline of Kampo medicine due to modernization by Western medicine during the late 19th century (Meiji period), education about Kampo medicine is currently included in Japanese curricula in most schools of medicine. Therefore, medical doctors in Japan prescribe the Kampo formulae to treat diseases (e.g., influenza, cold, and postmenopausal syndrome) and predisease, which is presymptomatic disease or an unhealthy condition without clear symptoms.

Each Kampo medicine consists of several "crude drugs" most of which are derived from medicinal plants. Therefore, a Kampo medicine is also designated a Kampo formula. During Japanization in the 18th century, the formulas showing adverse effects have been eliminated. The specifications and standards of general Kampo formulas and crude drugs are strictly defined by the Japanese Pharmacopoeia, which describes 34 Kampo formulas and 157 constituent crude drugs [1]. When other Kampo formulas that are not included in the Japanese Pharmacopoeia are added, 148 total Kampo formulas are used in Japan at present. Crude drugs of Kampo medicine are extracted by hot water and dried in vacuo, and the resultant powder is granulated and packaged in small sachets as Kampo extract products. 
Edible plants, including herbs, fruits, and vegetables, can be used as "functional foods," which have certain function(s). The definition of functional foods is different depending countries and laws. For example, the Functional Food Center defines functional foods as "natural or processed foods that contain biologically active compounds; which, in defined, effective non-toxic amounts, provide a clinically proven and documented health benefit utilizing specific biomarkers, for the prevention, management, or treatment of chronic disease or its symptoms" [2].

Pharmacologically active constituents are more highly abundant in the crude drugs of Kampo medicine than in foods and functional foods. In Japan, the usage of herbs and plants is classified by pharmacological activity into two classes (primarily medical use and nonmedical use) by the Ministry of Health, Labor and Welfare, Japan [3]. Licorice (roots and stolons of Glycyrrhiza uralensis L.) is used as a constituent crude drug of Kampo medicine and a sweetener for foods. A part of one plant species is used for the crude drugs of Kampo medicine, and the other parts are used for foods. For example, the peel of Satsuma mandarin (Citrus unshiu) is used as a crude drug, whereas the inside is eaten as a fruit. The features of Kampo medicine are compared with those of functional foods in Table 1.

Table 1. Comparison of Kampo medicine and functional foods

\begin{tabular}{lll}
\hline & Kampo medicine & Functional foods \\
\hline Components & $\begin{array}{l}\text { Several crude drugs that are } \\
\text { selected as a formula }\end{array}$ & $\begin{array}{l}\text { Foods, processed foods, or } \\
\text { constituents derived from these } \\
\text { foods }\end{array}$ \\
\hline Action & $\begin{array}{l}\text { Combination of empirically } \\
\text { known effects of crude drugs }\end{array}$ & Mild pharmacological activity \\
\hline $\begin{array}{l}\text { Total } \\
\text { pharmacological } \\
\text { potency }\end{array}$ & High & Lower than drugs \\
\hline $\begin{array}{l}\text { Pharmacological } \\
\text { potency of } \\
\text { constituents }\end{array}$ & $\begin{array}{l}\text { High (principal constituents); } \\
\text { low to medium (other } \\
\text { constituents) }\end{array}$ & Low to medium (many cases) \\
\hline Constituent content & High & Low \\
\hline Purpose of use & To treat diseases and predisease & To improve health conditions \\
\hline
\end{tabular}

${ }^{*}$ See details in the text.

When comparing pharmacological potencies of Kampo medicines, those of functional foods are lower. When a functional food possesses high potency that is comparable with a drug, it may be classified to a drug. Therefore, pharmacologically active (bioactive) constituents of functional foods generally show low to medium potency, whereas pharmacologically active constituents (i.e., principal constituents) in Kampo medicine show high potency. A highly 
potent constituent is sometimes present in a functional food, although its content is generally very low. Because the pharmacological effect of a constituent is determined by its pharmacological potency and content, the total potency of the functional food is not high in these cases.

\section{VERIFICATION OF PHARMACOLOGICAL EFFECTS ON HUMANS}

Functional foods and Japanese Kampo medicine must have beneficial effects on humans. The effects of Kampo medicine have been empirically evaluated by clinical administration for a long time. Due to a low abundance of pharmacologically active constituents, the pharmacological effectiveness of all functional foods has not been well evaluated. Therefore, the effects of functional foods on humans should be better investigated to increase the numbers of people who take functional foods to improve their health conditions. A safety test and toxicity assessment of functional foods are essential. Furthermore, a randomized, double-blind study with a placebo control is preferable to analyze the effects of the supplementation of a functional food.

Several levels are used to qualify functional foods and Kampo medicine (Figure 1). Significant evidence of pharmacological activity at the cell and animal levels is essential for human use of functional foods, although functional foods are prepared from foods or edible plants. To develop a new drug from functional foods or Kampo medicines, the order from cells to animals to humans is strict. A constituent in functional foods or Kampo medicine that is pharmacologically effective can serve as a lead compound for the synthesis of a new drug with maximum effect.

\begin{tabular}{|l|}
\hline $\begin{array}{l}\text { Cell } \\
\text { Biological and } \\
\text { physiological effects } \\
\text { Action of constituents } \\
\text { Molecular mechanisms } \\
\text { of action }\end{array}$ \\
\hline
\end{tabular}

Figure 1. Qualification and development of drugs and functional foods. The points to be examined at each level are indicated in the boxes.

\section{ISOLATION OF PHARMACOLOGICALLY ACTIVE CONSTITUENTS FROM CRUDE DRUGS AND FUNCTIONAL FOODS}

Purification of their constituents are essential to clarify pharmacological effects because each crude drug from Kampo medicine or a functional food consists of many constituents. For a variety of pharmacological analyses, the constituents should be isolated from crude drugs of Kampo medicine or functional foods to identify their chemical structures. Isolating and identifying principal constituents from functional foods is more difficult than isolating crude 
drugs from Kampo formulas due to the low content and low pharmacological activity of the constituents in functional foods.

Extracts are prepared from functional foods or crude drugs of Kampo medicine using hot water or an organic solvent (e.g., methanol and ethanol). Hot-water extraction (decoction) is often used to prepare Kampo medicine, and hydrophilic constituents are more recovered by this method than methanol extraction. Next, the extract is often fractionated by hydrophobicity into three crude fractions, including ethyl acetate-soluble, $n$-butanol-soluble, and water-soluble fractions [4]. The resultant fractions are further purified by various methods, such as silica gel chromatography, thin-layer chromatography (TLC), or high-performance liquid chromatography (HPLC), to identify the effective constituents. Their chemical structures are determined by nuclear magnetic resonance (NMR) and mass spectra analyses [for example, $5,6]$.

Anti-inflammatory effects were examined by monitoring the production of a proinflammatory mediator. Therefore, measurement of the levels of pro-inflammatory mediators will help isolation and identification of pharmacologically active constituents in both Kampo medicines and functional foods. For example, adenosine was identified as a hepatoprotective constituent in standardized extract of cultured Lentinula edodes mycelia (ECLM, AHCC $\left.{ }^{\circledR}\right)$ [7].

\section{EVALUATION AND DISCUSSION OF ANTI-INFLAMMATORY EFFECTS USING CELL-BASED ASSAYS}

Once the constituents are purified from crude drugs of Kampo medicine or functional foods and identified, they are ready to be examined. Cell-based studies are common for a variety of functional food and Kampo medicine analyses. For example, primary cultured rat hepatocytes are used as a liver injury model. In response to the pro-inflammatory cytokine interleukin (IL)$1 \beta$, pro-inflammatory mediators, such as nitric oxide (NO), pro-inflammatory cytokines, including tumor necrosis factor $\alpha(\mathrm{TNF}-\alpha)$ and IL-6, and chemokines are produced $[8,9]$. These pro-inflammatory mediators in the conditioned medium and the cells can be detected by enzyme-linked immunosorbent assay (ELISA) and western blot analysis [for example, 9]. The levels of their mRNAs are analyzed by northern blot analysis and reverse transcriptionpolymerase chain reaction (RT-PCR).

When a functional food, Kampo medicine, or a constituent is added to the medium, the production of these pro-inflammatory mediators is decreased in a dose-dependent manner. A half-maximal inhibitory concentration $\left(\mathrm{IC}_{50}\right)$ is calculated unless cytotoxicity is observed. The $\mathrm{IC}_{50}$ values are used to compare anti-inflammatory potencies. Macrophages, including macrophage lines (e.g., RAW264.7), are often used to evaluate anti-inflammatory effects in response to the bacterial endotoxin lipopolysaccharide (LPS) $[9,10]$. Macrophages produce pro-inflammatory mediators, including NO, prostaglandins, and pro-inflammatory cytokines. Differences in $\mathrm{IC}_{50}$ values for the suppression of NO production have been found between 
macrophage lines and rat hepatocytes [9]. Therefore, the anti-inflammatory activity of functional foods and Kampo medicine can be easily estimated using these systems.

The effects on the expression of many genes encoding inducible nitric oxide synthase (iNOS), cyclooxygenase 2 (COX2; i.e., prostaglandin-endoperoxide synthase 2, which produces prostaglandin $\mathrm{H}_{2}$ ), pro-inflammatory cytokines, and chemokines can be analyzed in cells at the molecular level by a variety of methods. These methods include those such as western blot analysis, ELISA, northern blot analysis, and RT-PCR. Transcriptional regulation by transcription factors and post-translational regulation, such as phosphorylation, can be also analyzed to examine the effects or functional foods and Kampo medicine. Functional foods were also investigated using animal and human studies (Table 2). These approaches may clarify the molecular mechanisms of action of these drugs and the pathophysiology of various diseases.

Table 2. Anti-inflammatory effects of functional foods

\begin{tabular}{|c|c|c|c|}
\hline Constituent & Origin & Verification $^{*}$ & References \\
\hline $\begin{array}{l}\text { Standardized extract of cultured } \\
\text { Lentinula edodes mycelia } \\
\left(\text { ECLM, AHCC }()^{* *}\right.\end{array}$ & $\begin{array}{l}\text { Lentinula edodes } \\
\text { (mushroom) }\end{array}$ & $\mathrm{H}, \mathrm{A}, \mathrm{C}$ & $\begin{array}{l}\text { Matsui et al. [11], Nakatake et } \\
\text { al. [12], Matsui et al. [13] }\end{array}$ \\
\hline Chlorogenic acid & $\begin{array}{l}\text { Flowers and buds of } \\
\text { Lonicera japonica, } \\
\text { coffee, etc. }\end{array}$ & $\mathrm{H}, \mathrm{A}, \mathrm{C}$ & $\begin{array}{l}\text { Ohno et al. [4], Farah et al. } \\
\text { [14], Xu et al. [15] }\end{array}$ \\
\hline Curcumin & $\begin{array}{l}\text { Rhizome of Curcuma } \\
\text { longa (turmeric) }\end{array}$ & $\mathrm{H}, \mathrm{A}, \mathrm{C}$ & $\begin{array}{l}\text { Rahmani et al. [16], Nakatake } \\
\text { et al. [17] }\end{array}$ \\
\hline $\begin{array}{l}\text { Standardized extract of } \\
\text { Asparagus officinalis stem (EAS, } \\
\text { ETAS } \AA 50)^{* *}\end{array}$ & $\begin{array}{l}\text { Stems of Asparagus } \\
\text { officinalis (asparagus) }\end{array}$ & $\mathrm{H}, \mathrm{A}, \mathrm{C}$ & $\begin{array}{l}\text { Ito et al. [18,19], Nishizawa et } \\
\text { al. [20] }\end{array}$ \\
\hline $\begin{array}{l}\text { Standardized oligomerized- } \\
\text { polyphenol from Litchi chinensis } \\
\text { fruit extract (OPLFE, } \\
\left.\text { Oligonol }{ }^{*}\right)^{* *}\end{array}$ & $\begin{array}{l}\text { Fruit of Litchi chinensis } \\
\text { (lychee) }\end{array}$ & $\mathrm{H}, \mathrm{A}, \mathrm{C}$ & $\begin{array}{l}\text { Ogasawara et al. [21], } \\
\text { Nishizawa et al. [22], } \\
\text { Yamanishi et al. [23] }\end{array}$ \\
\hline Perilla extract & $\begin{array}{l}\text { Leaves of Perilla } \\
\text { frutescens (green perilla) }\end{array}$ & $\mathrm{H}, \mathrm{A}, \mathrm{C}$ & $\begin{array}{l}\text { Ueda \& Yamazaki [24], Ueda } \\
\text { et al. [25], Baba et al. [26], } \\
\text { Nakajima et al. [27] }\end{array}$ \\
\hline pyroGlu-Leu (pEL) & $\begin{array}{l}\text { Wheat gluten } \\
\text { hydrolysate }\end{array}$ & $\mathrm{H}, \mathrm{A}, \mathrm{C}$ & $\begin{array}{l}\text { Kiyono et al. [28], Oishi et al. } \\
\text { [29], Sato et al. [30] }\end{array}$ \\
\hline
\end{tabular}

${ }^{*} \mathrm{H}$, human trial, or used as a food or a Kampo medicine; A, animal experiment; C, cell-based assay. ${ }^{* *}$ AHCC ${ }^{\circledR}$, ETAS ${ }^{\circledR} 50$, and Oligonol ${ }^{\circledR}$ are trademarks of Amino Up Co., Ltd., Sapporo, Japan.

The anti-inflammatory effects of many Kampo formulas (e.g., Inchinkoto, Ninjinyoeito, and Saireito) and their constituents (e.g., flavonoids, alkaloids, and phenylpropanoids) have been analyzed, as shown in Table 3. Please note that some of the constituents also included in foods and functional foods (e.g., chlorogenic acid). In Japan, there is legal classification, which 
discriminates crude drugs (i.e., primarily medicinal use) and others (e.g., foods) [3], whereas functional foods are differently defined the Japanese laws.

Table 3. Anti-inflammatory effects of crude Kampo medicine drugs and their constituents

\begin{tabular}{|c|c|c|c|}
\hline Constituent & Origin & Use $^{*}$ & References \\
\hline Inchinkoto & $\begin{array}{l}\text { Three crude drugs (Kampo } \\
\text { formula) }\end{array}$ & K & $\begin{array}{l}\text { Arai et al. [31], Matsuura et al. } \\
\text { [32] }\end{array}$ \\
\hline Ninjinyoeito & $\begin{array}{l}\text { Twelve crude drugs (Kampo } \\
\text { formula) }\end{array}$ & $\mathrm{K}$ & $\begin{array}{l}\text { Cyong et al. [33], Tanaka et al. } \\
\text { [34] }\end{array}$ \\
\hline Saireito & $\begin{array}{l}\text { Twelve crude drugs (Kampo } \\
\text { formula) }\end{array}$ & K & $\begin{array}{l}\text { Watanabe et al. [35], Miki et al. } \\
\text { [36] }\end{array}$ \\
\hline Gomisin $\mathrm{N}$ & Fruit of Schisandra chinensis & K & $\begin{array}{l}\text { Oh et al. [10], Takimoto et al. } \\
\text { [37] }\end{array}$ \\
\hline Isoliquiritin & $\begin{array}{l}\text { Roots and stolons of } \\
\text { Glycyrrhiza uralensis (licorice) }\end{array}$ & $\mathrm{F}, \mathrm{K}$ & $\begin{array}{l}\text { Tanemoto et al. [6], Asl \& } \\
\text { Hosseinzadeh [38] }\end{array}$ \\
\hline Limonin & $\begin{array}{l}\text { Bark of Phellodendron } \\
\text { amurense }\end{array}$ & $\mathrm{K}$ & Fujii et al.[5], Leu et al. [39] \\
\hline Nobiletin & $\begin{array}{l}\text { Peel of Citrus unshiu (Satsuma } \\
\text { mandarin) }\end{array}$ & $\mathrm{F}, \mathrm{K}$ & $\begin{array}{l}\text { Nogata et al. [40], Yoshigai et } \\
\text { al. [41] }\end{array}$ \\
\hline Shisoflavanone A & $\begin{array}{l}\text { Leaves of Perilla frutescens } \\
\text { (green perilla) }\end{array}$ & $\mathrm{F}, \mathrm{K}$ & $\begin{array}{l}\text { Ueda \& Yamazaki [24], Ueda et } \\
\text { al. [25], Baba et al. [26], } \\
\text { Nakajima et al. [27] }\end{array}$ \\
\hline
\end{tabular}

K, used for Kampo medicine. F, used as foods or functional foods.

\section{EVALUATION AND DISCUSSION OF ANTI-INFLAMMATORY EFFECTS USING ANIMAL MODELS}

Animal experiments using disease models are often performed to evaluate anti-inflammatory effects of not only drugs, but also Kampo medicines and functional foods. Sepsis is characterized by systemic inflammatory responses induced by infection [42]. Initially, bacterial endotoxin (lipopolysaccharide, LPS) causes endotoxemia, which triggers systemic inflammation, followed by multiple organ failure (i.e., sepsis). Therefore, endotoxemia/sepsis model animals are widely used to evaluate anti-inflammatory effects (Table 4). LPS and Dgalactosamine is administered to rats or mice to evoke endotoxemia and sepsis with liver failure $[43,44]$. Although LPS alone causes endotoxemia, it does not lead to sepsis in all animals [45]. D-Galactosamine (i.e., an inhibitor of RNA synthesis) causes a liver injury (hepatitis) and provokes sepsis when administered with LPS [46]. The levels of pro-inflammatory mediators can be monitored in these model animals. 
Table 4. Examples of endotoxemia and sepsis models in mice and rats

\begin{tabular}{|l|l|l|}
\hline Method & Description & Reference \\
\hline $\begin{array}{l}\text { D-Galactosamine and } \\
\text { LPS administration }\end{array}$ & $\begin{array}{l}\text { D-Galactosamine and LPS are simultaneously } \\
\text { administered; endotoxemia and sepsis are } \\
\text { associated with D-galactosamine-induced liver } \\
\text { failure }\end{array}$ & $\begin{array}{l}\text { Tanaka et al. [43], } \\
\text { Miki et al. [44] }\end{array}$ \\
\hline $\begin{array}{l}\text { Partial hepatectomy } \\
\text { and LPS administration }\end{array}$ & $\begin{array}{l}\text { After partial (70\%) hepatectomy, LPS is } \\
\text { administered; endotoxemia and sepsis are } \\
\text { associated with liver failure by partial hepatectomy }\end{array}$ & $\begin{array}{l}\text { Nakatake et al. } \\
\text { [12], Tsuji et al. } \\
\text { [47] }\end{array}$ \\
\hline $\begin{array}{l}\text { Cecal ligation and } \\
\text { puncture (CLP) }\end{array}$ & $\begin{array}{l}\text { After ligation, the caecum is punctured to release } \\
\text { the contents (feces) into the peritoneal cavity and } \\
\text { evoke peritonitis }\end{array}$ & $\begin{array}{l}\text { Wichterman et al. } \\
\text { [49], Dejager et } \\
\text { al. [50] }\end{array}$ \\
\hline
\end{tabular}

Alternatively, a partial hepatectomy followed by LPS administration is used as another endotoxemia model with liver failure [47]. In these experimental models, endotoxemia initiates after injection of LPS. Administration of an effective functional food or Kampo medicine improves the survival of endotoxemia model animals. For example, a standardized extract of cultured Lentinula edodes mycelia (AHCC®) had protective effects on endotoxemia model rats with liver failure after hepatectomy [12]. The mRNAs encoding pro-inflammatory mediators in the partial hepatectomy/LPS model rats expressed more than those in the Dgalactosamine/LPS model rats [48].

The cecal ligation and puncture (CLP) model is also used to mimic human sepsis [49,50]. This sepsis model leads to the growth of intestinal bacteria and the subsequent release of LPS from dead bacteria in parallel during peritonitis caused by the bacteria. The released LPS leads to endotoxemia, and then sepsis occurs with multiple organ failure. Because the onset and severity of sepsis may change by each animal, the reproducibility of this model is not very high.

\section{CONCLUSION}

The principles and methods to assess anti-inflammatory effects of Kampo medicine and functional foods are reviewed. The same methods can be applied to assess the pharmacological effects of both functional foods and Kampo medicine at the cell and animal levels. These studies will provide evidence for the mechanisms of action of functional foods and Kampo medicines. Furthermore, accumulating data will become the basis for the development of safe and effective functional foods and will improve health conditions and prevent disease.

List of Abbreviations: NO, nitric oxide; IL, interleukin; $\mathrm{IC}_{50}$, half-maximal inhibitory concentration; TNF- $\alpha$, tumor necrosis factor $\alpha . ;$ LPS, lipopolysaccharide. 
Competing Interests: None declared.

Authors' Contributions: All authors contributed to this review.

Acknowledgments and Funding: We thank Ms. Noriko Kanazawa for her secretarial assistance. This work was supported in part by the Asia-Japan Research Institute of Ritsumeikan Asia-Japan Research Organization, Ritsumeikan University (Ibaraki, Osaka, Japan).

\section{REFERENCES}

1. The Japanese Pharmacopoeia. [http://www.mhlw.go.jp/stf/seisakunitsuite/bunya/00000 66597.html]

2. Functional Food Center [https://www.functionalfoodscenter.net.]

3. Ministry of Health, Labour and Welfare [https://www.mhlw.go.jp/file/06Seisakujouhou-11130500-Shokuhinanzenbu/040601-001_1.pdf]

4. Ohno N, Yoshigai E, Okuyama T, et al.: Chlorogenic acid from the Japanese herbal medicine Kinginka (Flos Lonicerae japonicae) suppresses the expression of inducible nitric oxide synthase in rat hepatocytes. HOAJ Biol 2012, 1: 1-10.

5. Fujii A, Okuyama T, Wakame K, Okumura T, Ikeya Y, Nishizawa M: Identification of anti-inflammatory constituents in Phellodendri Cortex and Coptidis Rhizoma by monitoring the suppression of nitric oxide production. J Nat Med 2017, 71(4): 745-756.

6. Tanemoto R, Okuyama T, Matsuo H, Okumura T, Ikeya Y, Nishizawa M: The constituents of licorice (Glycyrrhiza uralensis) differentially suppress nitric oxide production in interleukin-1 $\beta$-treated hepatocytes. Biochem Biophys Rep 2015, 2: 153 159

7. Tanaka Y, Ohashi S, Ohtsuki A, et al.: Adenosine, a hepato-protective component in active hexose correlated compound: its identification and iNOS suppression mechanism. Nitric Oxide 2014, 40: 75-86.

8. Yoshigai $\mathrm{E}$, Hara $\mathrm{T}$, Inaba $\mathrm{H}$, et al.: Interleukin-1 $\beta$ induces tumor necrosis factor- $\alpha$ secretion from rat hepatocytes. Hepatol Res 2014, 44(5): 571-583.

9. Inaba H, Yoshigai E, Okuyama $\mathrm{T}$, et al.: Antipyretic analgesic drugs have different mechanisms for regulation of the expression of inducible nitric oxide synthase in hepatocytes and macrophages. Nitric Oxide 2015, 44: 61-70.

10. Oh SY, Kim YH, et al.: Anti-inflammatory effects of gomisin $\mathrm{N}$, gomisin $\mathrm{J}$, and schisandrin C isolated from the fruit of Schisandra chinensis. Biosci Biotechnol Biochem 2010, 74(2): 285-291. 
11. Matsui Y, Uhara J, Satoi S, et al.: Improved prognosis of postoperative hepatocellular carcinoma patients when treated with functional foods: a prospective cohort study. J Hepatol 2002, 37(1): 78-86.

12. Nakatake R, Tanaka Y, Ueyama Y, et al.: Protective effects of active hexose correlated compound in a rat model of liver injury after hepatectomy. Functional Foods in Health and Disease 2016, 6(11): 702-717.

13. Matsui K, Kawaguchi Y, Ozaki T, et al.: Effect of active hexose correlated compound on the production of nitric oxide in hepatocytes. JPEN J Parenter Enteral Nutr 2007, 31(5): 373-380.

14. Farah A, Monteiro M, Donangelo CM, Lafay S: Chlorogenic acids from green coffee extract are highly bioavailable in humans. J Nutr 2008, 138(12): 2309-2315.

15. Xu Y, Chen J, Yu X, et al.: Protective effects of chlorogenic acid on acute hepatotoxicity induced by lipopolysaccharide in mice. Inflamm Res 2010, 59(10): 871-877.

16. Rahmani S, Asgary S, Askari G, et al.: Treatment of non-alcoholic fatty liver disease with curcumin: A randomized placebo-controlled trial. Phytother Res 2016, 30(9): 15401548.

17. Nakatake R, Hishikawa H, Matushima H, et al.: Curcumin protects liver inflammation by suppressing expression of inducible nitric oxide synthase in primary cultured rat hepatocytes. Functional Foods in Health and Disease 2017, 7(9): 716-734.

18. Ito T, Sato A, Ono T, et al.: Isolation, structural elucidation, and biological evaluation of a 5-hydroxymethyl-2-furfural derivative, asfural, from enzyme-treated asparagus extract. J Agric Food Chem 2013, 61(38): 9155-9159.

19. Ito T, Maeda T, Goto K: Enzyme-treated asparagus extract promotes expression of heat shock protein and exerts antistress effects. J Food Sci 2014, 79(3): H413-419.

20. Nishizawa M, Kano M, Okuyama T, Okumura T, Ikeya Y: Anti-inflammatory effects of enzyme-treated asparagus extract and its constituents in hepatocytes. Functional Foods in Health and Disease 2016, 6(2): 91-109.

21. Ogasawara J, Kitadate K, Nishioka H, et al.: Comparison of the effect of oligonol, a new lychee fruit-derived low molecular form of polyphenol, and epigallocatechin-3-gallate on lipolysis in rat primary adipocytes. Phytother Res 2011, 25(3): 467-471.

22. Nishizawa M, Hara T, Miura T, et al.: Supplementation with a flavanol-rich lychee fruit extract influences the inflammatory status of young athletes. Phytother Res 2011, 25(10): 1486-1493.

23. Yamanishi R, Yoshigai E, Okuyama T, et al.: The anti-inflammatory effects of flavanolrich lychee fruit extract in rat hepatocytes. PLoS One 2014, 9(4): e93818. 
24. Ueda H, Yamazaki M: Anti-inflammatory and anti-allergic actions by oral administration of a perilla leaf extract in mice. Biosci Biotechnol Biochem 2001, 65(7): 1673-1675.

25. Ueda H, Yamazaki C, Yamazaki M: Luteolin as an anti-inflammatory and anti-allergic constituent of Perilla frutescens. Biol. Pharm. Bull 2002, 25(9):1197-1202.

26. Baba S, Osakabe N, Natsume M, et al.: Absorption, metabolism, degradation and urinary excretion of rosmarinic acid after intake of Perilla frutescens extract in humans. Eur $\mathbf{J}$ Nutr 2005, 44(1): 1-9.

27. Nakajima A, Yamamoto Y, Yoshinaka N, et al.: A new flavanone and other flavonoids from green perilla leaf extract inhibit nitric oxide production in interleukin $1 \beta$-treated hepatocytes. Biosci Biotechnol Biochem 2015, 79(1): 138-146.

28. Kiyono T, Hirooka K, Yamamoto Y, et al.: Identification of pyroglutamyl peptides in Japanese rice wine (sake): presence of hepatoprotective pyroGlu-Leu. J Agric Food Chem 2013, 61(47): 11660-11667.

29. Oishi M, Kiyono T, SatoK, et al.: pyroGlu-Leu inhibits the induction of inducible nitric oxide synthase in interleukin-1 $\beta$-stimulated primary cultured rat hepatocytes. Nitric Oxide 2015, 44: 81-87.

30. Sato K, Egashira Y, Ono S, et al.: Identification of a hepatoprotective peptide in wheat gluten hydrolysate against D-galactosamine-induced acute hepatitis in rats. J Agric Food Chem 2013, 61(26): 6304-6310.

31. Arai M, Yokosuka O, Fukai K, et al.: A case of severe acute hepatitis of unknown etiology treated with the Chinese herbal medicine Inchinko-to. Hepatol Res 2004, 28(3): 161-165.

32. Matsuura T, Kaibori M, Araki Y, et al.: Japanese herbal medicine, inchinkoto, inhibits inducible nitric oxide synthase induction in interleukin-1 $\beta$-stimulated hepatocytes. Hepatol Res 2012, 42(1): 76-90.

33. Cyong JC, Ki SM, Iijima K, Kobayashi T, Furuya M: Clinical and pharmacological studies on liver diseases treated with Kampo herbal medicine. Am J Chin Med 2000, 28(3-4): 351-360.

34. Tanaka Y, Kaibori M, Miki H, et al.: Japanese Kampo medicine, ninjinyoeito, inhibits the induction of iNOS gene expression in proinflammatory cytokine-stimulated hepatocytes. Br J Pharmaceut Res 2014, 4(19): 2226-2244.

35. Watanabe T, Yamamoto T, Yoshida M, et al.: The traditional herbal medicine saireito exerts its inhibitory effect on murine oxazolone-induced colitis via the induction of Th1polarized immune responses in the mucosal immune system of the colon. Int Arch Allergy Immunol 2010, 151(2): 98-106. 
36. Miki H, Tokuhara K, Oishi M, et al.: Japanese Kampo Saireito has a liver-protective effect through the inhibition of inducible nitric oxide synthase induction in primary cultured rat hepatocytes. JPEN J Parenter Enteral Nutr 2016, 40(7):1033-1041.

37. Takimoto Y, Qian HY, Yoshigai E, Okumura T, Ikeya Y, Nishizawa M. Gomisin N: in the herbal drug gomishi (Schisandra chinensis) suppresses inducible nitric oxide

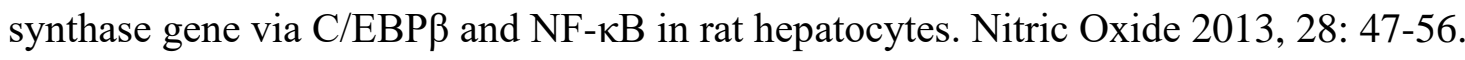

38. Asl MN, Hosseinzadeh H: Review of pharmacological effects of Glycyrrhiza sp. and its bioactive compounds. Phytother Res 2008, 22(6): 709-724.

39. Leu CH, Li CY, Yao X, Wu TS: Constituents from the leaves of Phellodendron amurense and their antioxidant activity. Chem Pharm Bull (Tokyo) 2006, 54 (9): 1308-1311.

40. Nogata Y, Sakamoto K, Shiratsuchi H, Ishii T, Yano M, Ohta H: Flavonoid composition of fruit tissues of citrus species. Biosci Biotechnol Biochem 2006, 70(1): 178-192.

41. Yoshigai E, Machida T, Okuyama T, et al.: Citrus nobiletin suppresses inducible nitric oxide synthase gene expression in interleukin-1 $\beta$-treated hepatocytes. Biochem Biophys Res Commun 201, 439(1): 54-59.

42. Singer M, Deutschman CS, Seymour CW, et al.: The Third International Consensus Definitions for Sepsis and Septic Shock (Sepsis-3). JAMA 2016, 315(8): 801-810.

43. Tanaka H, Uchida Y, Kaibori M, et al.: $\mathrm{Na}^{+} / \mathrm{H}^{+}$exchanger inhibitor, FR183998, has protective effect in lethal acute liver failure and prevents iNOS induction in rats. $\mathrm{J}$ Hepatol 2008, 48(2): 289-299.

44. Miki H, Tokuhara K, Oishi M, et al.: Elental amino acid component has protective effects on primary cultured hepatocytes and a rat model of acute liver injury. Nutr Res 2017, 42: 71-84.

45. Makowka L, Falk RE, Rotstein LE, et al.: Reversal of experimental acute hepatic failure in the rat. J Surg Res 1980, 29(6): 479-487.

46. Decker K, Keppler D: Galactosamine hepatitis: key role of the nucleotide deficiency period in the pathogenesis of cell injury and cell death. Rev Physiol Biochem Pharmacol 1974, 71: 77-106.

47. Tsuji K, Kwon AH, Yoshida $\mathrm{H}$, et al.: Free radical scavenger (edaravone) prevents endotoxin-induced liver injury after partial hepatectomy in rats. J Hepatol 2005, 42(1):94-101.

48. Okuyama T, Nakatake R, Kaibori M, Okumura T, Kon M, Nishizawa M: A sense oligonucleotide to inducible nitric oxide synthase mRNA increases the survival rate of rats in septic shock. Nitric Oxide 2018, 72:32-40. 
49. Wichterman KA, Baue AE, Chaudry IH: Sepsis and septic shock--a review of laboratory models and a proposal. J Surg Res 1980, 29(2): 189-201.

50. Dejager L, Pinheiro I, Dejonckheere E, Libert C: Cecal ligation and puncture: the gold standard model for polymicrobial sepsis? Trends Microbiol 2011, 19(4): 198-208. 